gluten. The diameter of each filament is one 16,000 th of an inch.

Frederic Carpenter Skey (1798-1872) was a pupil of Abernethy and became successively assistantsurgeon, lecturer on anatomy and surgeon at St. Bartholomew's Hospital. He was elected F.R.S. in 1837 and in 1863 served as president of the Royal College of Surgeons.

\section{Royal College of Surgeons}

TrE London Medical Gazette of February 18 contains the following eulogy of the Royal College of Surgeons :

"Of the existing institutions connected with the medical profession the College of Surgeons is in various respects by far the most important. The building is worthy of the great national establishment; the library is a magnificent addition, which has grown up of late years; the museum is a monument worthy of the name it bears, and creditable to the nation. Nor do the names of many among its present members reflect less honour upon English surgery than the greatest of their predecessors, while of the existing Council it is but justice to add that they have shown their determination to keep pace with the march of intellect and the improvement of the times. In these respects -we mean setting aside ancient prejudices - in gathering wisdom from passing events - and in rendering their institution available to great national objects-we must say they have far outstript their elder brethren in Pall Mall, and accordingly are their character and influence as a public body proportionately greater. It is in Lincoln's Inn Fields that the battle between the new and the old race of practitioners must be fought. . . ."

\section{University Events}

Cambridge.--Prof. J. Proudman will give a course of six lectures on dynamical oceanography in the Zoological Lecture Theatre at 5 p.m. on Mondays, Wednesdays and Fridays, commencing on Monday, February 15.

The following have been approved for the degree of Sc.D. : D. A. Bannerman, of Pembroke College, and E. A. Guggenheim, of Gonville and Caius College. Miss Frances Mary Hamer, of Girton College, has been approved for the title of the degree of Sc.D.

Edinburgh.--The Cameron Prize for 1937 has been awarded by the Senatus to Prof. J. Bertram Collip, professor of biochemistry in McGill University, Montreal, in recognition of his many contributions to endocrine therapy and in particular his work on the parathyroid gland.

At a meeting of the University Court on January 25, an offer was received from the University Grants Committee of a non-recurrent capital grant up to a maximum of $£ 15,000$ towards the cost of a building for a Students' Union for men and women on the King's Building site at West Mains Road, the building to include a refectory and a gymnasium. The total cost, exclusive of furnishings, is estimated at $£ 20,000$, and the Committee has offered the grant on condition that the remainder of the cost be obtained from other sources, and that the scheme should be proceeded with as soon as possible, and in any case within two years from the date of the offer.

\section{Societies and Academies}

\section{London \\ Royal Society, February 4.}

R. A. Watson Watt, A. F. Wrukins and E. G. BOWEN : The return of radio waves from the middle atmosphere. Observations spread over a year from May 1935 have established the existence of sustained stratified electrification, persisting for several days, of such ionization density and gradient as to return radio waves of frequency $6-12 \mathrm{Mc} / \mathrm{sec}$. at vertical incidence, at such heights as $8 \cdot 5,9 \cdot 3,10 \cdot 3,10 \cdot 75$ and $13.5 \mathrm{~km}$. with reflection coefficients of the order of $0 \cdot 7$, giving measurable echoes up to the tenth order, beyond which they are not readily distinguished from ionospheric echoes. Apparently independent stratification at $45-50 \mathrm{~km}$., with a reflection coefficient of 0.3 for $6 \mathrm{Mc} / \mathrm{sec}$. waves, and the $D$ region at and above $60 \mathrm{~km}$. are also recorded. Reflections from all these regions are obtained at and above the frequencies proposed for television services. The ionization does not fall to very low values at night, and has no seasonal variation of large amplitude. Evidence is given of replenishment around the $20-30 \mathrm{~km}$. levels by local thunderstorms.

H. J. Bhabba and W. Heitler: The passage of fast electrons and the theory of cosmic showers. Relativistic quantum mechanies have been used to calculate the number of secondary positive and negative electrons produced by a fast primary electron with energy $E_{0}$ passing through a layer of matter of thickness $l$. The primary electron in the field of a nucleus has a large probability of emitting a hard light quantum which creates a pair. The pair electrons emit again light quanta which create pairs, and so on. The number of secondaries increases rapidly with $E_{0}$. If an electron of $10^{11} \mathrm{e}$-volts passes through a lead plate of $5 \mathrm{~cm}$. thickness the number of particles emerging from the plate amounts to 1,000 or more. Thus showers can be explained by the ordinary quantum theory. Comparison with experiments shows that Rossi's transition curve and Regener's absorption curve in the atmosphere can be understood on this theory. The penetrating power of fast electrons appears to be very much greater than a straightforward consideration of the energy loss would indicate. The absorption coefficient of the radiation found at a depth of 100 metres of water cannot, however, be understood on the basis of this theory if this radiation is due to primary electrons.

\section{Paris}

Academy of Sciences, January 11 (C.R., 204, 77-160).

Marcel Godchot and Mrre. Germatne Cauquix. The action of hydrocyanic acid on 4-methylcyclohexanone and the preparation of the two stereoisomeric 4-methylhexanol carboxylic acids.

PAUL LÉVY: The arithmetic of the laws of prob ability.

Marc Courtand: Gauche curves of the third order.

Paul Vincensivi: Bodies of constant width in space of three dimensions.

ANDRÉ MARCHAUD: The contingent and paratingent at a point of a simple Jordan surface.

Michel Ghermanescu : Homofocal quadries.

Lours Thubauduer: The Poncelet polygons in scribed and circumscribed in two conics. 